\title{
PALAVRAS ALADAS: UMA PEQUENA TEORIA DO SUBLIME N'AS AVES DE ARISTÓFANES
}

\author{
Adriane da Silva Duarte*
}

\begin{abstract}
RESUMO: A comédia As Aves de Aristófanes tem por tema principal o poder da palavra. Embora seu enredo possa parecer fantástico à primeira vista, a referência à democracia ateniense, cujo principal sustentáculo estava no debate público, está bem presente. Ao explorar as diversas possibilidades de usar as palavras para manipular os outros e atingir os objetivos mais ímprováueis, Aristófanes traz à cena os maiores beneficiários da retórica: poetas, adivinhos, advogados, políticos. Nos sucessivos embates com o herói, delineia-se uma pequena teoria do sublime, que busca descrever o efeito do discurso sobre o homem. Apesar da sua brevidade, sāo surpreendentes os pontos de contato com a definição apresentada séculos mais tarde por Longino no Tratado do Sublime.
\end{abstract}

Palauras-chave: Comédia Grega Antiga, Aristófanes, Sublime.

A comédia grega antiga é um gênero político caracterizado pela critica da esfera pública. Aristófanes, seu principal representante, não só abordou com frequeência temas como as distorçōes do sistema judiciário, a nova educaçāo, a demagogia, a guerra e a paz, como também satirizou abertamente figuras proeminentes da sua cidade natal. Nesse contexto, Atenas não é apenas o cenário natural desse teatro, mas também o seu principal objeto.

As Aves, comédia que data de 414 a. C., é uma das poucas peças que nos legou cuja ação não se passa em Atenas. Além disso,

(*) Professora de Lingua e Literatura Grega do Departamento de Letras Clássicas e Vernáculas, FFLCH/USP. 

$n^{\prime}$ As Aves de Aristófanes. Lingua e Literatura, n²3, p. 15-27, 1997.

sua trama tem apelo universal, aproximando-se do conto popular: o herói deixa sua cidade, descontente com as condições de vida, e parte ao encontro de um ser fantástico, uma ave que antes fora homem, para que esta lhe ajude na escolha de um lugar melhor para morar. Insatisfeito com as possibilidades apresentadas, resolve fundar em conjunto com os pássaros uma cidade aérea e aproveitar essa situação estratégica para estender o dominio deles sobre deuses e homens. Cabe ao herói, transformado em ave, conduzir o plano e colher os louros pela vitória; ao final da peça é sagrado o mestre soberano do universo.

A ausência de elementos de sátira direta a Atenas, em contraste com as peças anteriores, fez com que alguns helenistas classificassem As Aves ora como uma alegoria do momento político às vésperas da expedição à Sicília, ora como uma comédia de escape, uma tentativa de fugir da realidade para um mundo de faz-de-conta, ou ainda como uma utopia da vida pré-cívica ${ }^{1}$. De fato, num primeiro momento, o choque entre civilização e natureza parece nortear a construção do enredo, que opōe a degradação da cidade à simplicidade da floresta. Mas a idealizaçāo da vida natural nāo dura muito. Se a paisagem d'As Aves nāo evoca Atenas, seu protagonista é um ateniense, fato de extrema relevância para a análise de seus atos.

Já no prólogo, o protagonista e seu companheiro de viagem declaram sua cidadania ateniense e deixam claro que, embora estejam decepcionados com sua terra natal, não pretendem abdicar do meio urbano. Em sua bagagem trazem uma cesta, uma panela sacrificial e coroas de mirto, utensilios necessários para a cerimônia de consagração de uma cidade ${ }^{2}$. Desde o principio, eles contam com a possibilidade de, não encontrando um lugar apropriado, fundar a sua própria cidade. É com essa disposição que se dirigem a

(1) Para uma sintese das principais tendências interpretativas veja-se DOBROV (1990). Os defensores da alegoria. atribuem-na ao decreto de Siracúsio. que teria proibido a sátira pessoal em Atenas nesse período, obrigando os comediógrafos a trocarem as referências abertas por alusōes cifradas.

(2) As Aues, vv. 33-35 e 43. 
Tereu, um antigo rei transformado em poupa por Zeus ${ }^{3}$ para se aconselharem com ele.

A idéia de criar nos ares uma nova cidade surge quando os homens desistem de encontrar uma localidade existente que seja livre de defeitos e passam a observar a vida que as aves levam: sem preocupação com dinheiro, elas passam o dia nos campos em busca de sementes ${ }^{4}$. O que chama a atençāo do herói não é o bucólico diaa-dia em meio à natureza, mas a falta de objetivos do reino animal. Como ateniense, ele é um animal político, no sentido aristotélico do termo. Para Aristóteles, o homem sem cidade (ápolis) está ou acima ou abaixo da humanidade, ou é um deus ou é um bicho, por ser incapaz de sobrepor os interesses coletivos aos individuais e garantir, assim, a auto-suficiência. $O$ homem define-se por sua participação na comunidade, a opção natural de uma vida melhor ${ }^{5}$. Todo cidadāo tem uma mentalidade politica. Imediatamente vem ao herói o desafio de despertar nos pássaros a ambiçāo, introduzindo nas matas o virus do poder.

A palavra é o instrumento adequado para cooptar os bichos. A concepção do plano da cidade aérea deve-se a um trocadilho: por que não transformar o céu, pólo das aves, em uma pólis (cidade)? ${ }^{6}$ Nisso reside o poder futuro dos pássaros, desde que eles passem a obedecer ao herói. $O$ verbo grego para obedecer é o mesmo que para

(3) Segundo o mito, Tereu rei trácio, era casado com Procne, filha do rei ateniense Pandion e irmã de Filomela. Tereu, apaixonado, rapta Filomela e corta-lhe a lingua para evitar que ela o denuncie. Através de uma mensagem bordada, Filomela consegue comunicar-se com a irmã e as duas se vingam esquartejando e servindo como prato principal em um banquete Ítis, filho de Tereu e Procne. Como forma de puniçāo, os deuses transformam todos em aves: Tereu em poupa, Procne em rouxinol e Filomela em andorinha. $\mathrm{N}^{\prime}$ As Aves, as principais caracteristicas do mito sāo subvertidas, bem ao gosto da comédia. Tereu e Procne parecem estar reconciliados, pois dividem o mesmo ninho e ele, que foi responsável pela mudez de Filomela, por lhe ter cortado a lingua, torna-se um grande disseminador da linguagem ao ensinar aos pássaros a fala articulada (vv. 199-200).

(4) As Aves, v. 155 ss.

(5) Politica, 1253 a.

(6) As Aves, v. 184. 

$n^{\prime}$ As Aves de Aristófanes. Lingua e Literatura, $n^{\circ} 23$, p. 15-27, 1997.

persuadir, peitho e o nome do protagonista da comédia, Pisetero, é composto desse radical e do substantivo hetaîros, companheiro. Companheiro Persuasor ou, numa tradução mais livre, Bom de Lábia, subverte a partir de então a situação inicial da peça, em que os dois homens obedeciam uma gralha e um gaio, seguindo-as às cegas; agora são elas e as de sua espécie que se deixam persuadir e passam a obedece-lo ${ }^{7}$ Tem inicio um jogo de persuasão, em que o herói usa toda a sua habilidade lingüistica para convencer primeiro Tereu da necessidade de fundar a nova cidade, depois as demais aves e, por fim, os deuses a ceder a soberania.

Apresenta-se então o verdadeiro tema da peça: a palavra. As Aves é uma comédia sobre o poder do discurso e Pisetero, como seu nome mesmo indica, é um mestre no convencimento. A palavra de Pisetero é poderosa não só porque é capaz de alterar o mundo, mas também porque confere poder ao seu usuário. De uma figura fraca no começo da peça, o velho exilado torna-se no final lider dos pássaros, dos homens e dos deuses. Seu casamento com Soberania coloca-o acima do próprio Zeus, transformando-o em senhor do universo.

Essa qualidade da palavra só é imaginável no âmbito de uma cultura predominantemente oral e, mais ainda, numa democracia. Nenhum outro regime politico projetaria alguém tão alto sô por sua habilidade retórica. Para Vernant, o que caracteriza a pólis grega é "uma extraordinária preeminência da palavra sobre todos os outros instrumentos de poder ${ }^{\text {n8 }}$. Ela se torna o meio principal de subjugar os outros e passa a manter com a política uma relação de reciprocidade, pois se a política é a linguagem posta em prática, esta se molda necessariamente nas assembléias da ágora, na discussão. Nāo é à toa que as considerações de Aristóteles, na Politica, sobre o dom humano da fala se dão no mesmo contexto em que é exposta a inclinaçāo natural dos homens à vida em sociedade . $^{9}$

O debate, que constitui o grande sustentáculo da democracia, está em primeiro plano n'As Aves o que faz com que também Atenas

(7) As Aves, vv. 5 e 7, peithómenon; v. 163 ss., pisthoisthe, pithómetha, pithesthe.

(8) VERNANT (1981: 34).

(9) 1253 a. 
esteja permanentemente em foco, mesmo que as menções diretas sejam poucas. Tanto é assim que o regime democrático, um produto tipicamente ateniense, é de adoção universal na peça: as aves delegam a Pisetero o direito de representá-las junto aos deuses, que, por sua vez, elegem uma comissāo para negociar seus interesses.

A ascensão do herói cômico ao Olimpo, portanto, deve-se menos às asas, que ele porta desde a sua metamorfose em pássaro na metade da peça ${ }^{10}$, do que à eficácia de seu discurso. A relação entre asas e palavras não é nova para os gregos, tendo sido registrada primeiro no emprego homérico da fórmula palauras aladas lépea pteróenta). Mas se o sentido da expressão não é esclarecido em Homero, n'As Aves o vinculo entre esses elementos é constantemente reelaborado e explicitado ${ }^{11}$.

A asa constitui a principal imagem da peça, como se poderia deduzir já a partir do seu título. Alados, além dos pássaros, são alguns deuses e os protagonistas humanos, que adquirem a capacidade de voar após ingerirem uma raiz mágica. De marca de inferioridade, traço animalesco que atrapalha os planos de conquista das aves, elas se tornam, na argumentaçāo de Pisetero, um traço de união com os deuses, já que estes também voam. Embora para as aves as asas denotem comodidade, rapidez, segurança e status ${ }^{12}$, elas são sobretudo um símbolo ascencional. Voar é libertar-se do peso, do corpóreo, do terreno. $O$ vôo é, literalmente, uma sublimação, e a comédia não escapará a essas implicaçōes. A análise das três cenas em que Pisetero atende homens em busca de asas vai ser valiosa para a caracterização da relaçāo entre as asas e o sublime na comédia, assim como para a determinação do sentido desse termo para Aristófanes ${ }^{13}$.

(10) As Aves, v. 655.

(11) Cf. WHITMAN (1964: 193-194).

(12) ANDERSEN, H. C. Os novos trajes do imperador. In: Contos de Andersen.

Tradução de Guttorm Hanssen. Rio de Janeiro: Paz e Terra, 1987, p. 108-113.

(13) As Aves, vv. 676-800. 

$n^{\prime}$ As Aves de Aristófanes. Lingua e Literatura, n² 23, p. 15-27, 1997.

\section{ASAS: UM INSTRUMENTO PARA A ELEVAÇĀO DO ESPÍRITO.}

O primeiro a se apresentar é um jovem que declara desejar asas para poder agir como certas aves que costumam surrar o próprio pai até a morte. Sua intençāo é apoderar-se da herança sem ter que esperar que a natureza aja por si mesma. Convencido por Pisetero a mudar de idéia e a canalizar toda a sua agressividade para o serviço militar, ele será o único que receberá o que veio buscar, ainda que a maioria dos comentadores acredite que, nessa passagem, as asas representem um escudo para o novo soldado. A razão mais provável para isso, é que ele abandona os pensamentos rasteiros e aceita o conselho do herói. A recusa de Pisetero em ceder asas para propiciar más ações pressupõe uma incompatibilidade entre baixeza moral e a capacidade de voar. As asas estariam mais ligadas à idéia de elevação espiritual do que à pura ascensāo fisica.

O segundo visitante é apresentado de uma perspectiva estética, sem que hajam consideraçōes morais como no caso do seu antecessor. O poeta ditirâmbico Cinésias, contemporâneo de Aristófanes e satirizado pelos comédiógrafos por sua magreza e seu ateísmo, ilustra a visão aristofânica do sublime na poesia. Ao se apresentar a Pisetero, ele justifica seu desejo por asas para poder colher nos ares o material para sua arte:
“Após receber de vocè asas, quero, nas alturas
voando, das nuvens tirar novos,
movidos a ar, nevados prelúdios. [...]
Os mais brilhantes ditirambos
sāo aéreos, obscuros, azulados
e de ágeis-asas. ${ }^{14}$

O Cinésias d'As Aves é um obcecado por tudo que pertença às regiòes celestes. Esse seu interesse testemunha uma tendência do ditirambo no fim do século $\mathrm{V}$ a. C. que se caracteriza pelo esvazia- 
mento de conteúdo como contrapartida de sua crescente complexidade métrica e melódica. As narrativas mitológicas, que até então mantinham o sentido cultual do ditirambo, tornam-se apenas pretexto para o exercício de estilo e as digressões multiplicam-se ${ }^{15}$. Assim, a poesia aérea de Cinésias, povoada de nuvens, pássaros e brisas, parece estar cheia de vento, oca.

A natureza aérea dos novos ditirambos já havia sido descrita por Aristófanes n'A Paz, onde ele coloca os poetas, literalmente, nas alturas. Ao voltar do Olimpo, perguntado se encontrara outro mortal pelo caminho, o camponês Trigeu responde que:

"Nãol A nāo ser duas ou très almas (psychè) de poetas ditưâmbicos [...) a apanhar em vōo prelúdios musicais, daqueles que cruzam o céu. levados pelo vento. ${ }^{\text {"16 }}$

As almas dos poetas se lançam ao céu na esperança de elevar o estilo. O que move a sua ascensão é a busca do sublime, em grego hýpsos, literalmente altura, elevação ${ }^{17}$ Essa visão não é exclusiva da comédia, tanto que a comparação entre poetas e pássaros é recorrente na líica grega. E Cinésias nāo é exceçāo, jã que revela o desejo de tornar-se um rouxinol canoro ${ }^{18}$. Grotescamente, sua poesia reflete seu comportamento:

"Imagens dos alados,

etéreos corredores,

de pássaros de longo-colo. ${ }^{m 19}$

Há uma confusão intencional entre a poesia sublime e a de temática elevada. Aristófanes opera uma redução do sentido figura-

(15) Cf. COMOTTI (1991: 24).

(16) A Paz, vv. 827-831, tradução de Maria de Fátima Souza e Silva (1989). Itálico da autora.

(17) O termo sublime deriva do adjetivo latino sublimis, o que está no alto, o que è elevado: figuradamente se aplica ao estilo.

(18) As Aves, v. 1380.

(19) As Aves, v. 1393-1394, tradução da autora. 
do de tó hýpsos, o estilo elevado, para o literal, altura. Cinésias, uma metáfora ambulante, encarna o autor sublime, o poeta-pássaro que eleva a si e à sua arte para os ares. Do ponto de vista estético, as asas são um instrumento de acesso ao sublime. $O$ fato de $o$ poeta partir sem elas mostra que a sua concepção de sublime, que certamente pode ser estendida a vários colegas seus, é equivocada aos olhos do comediógrafo. $\mathrm{E}$ isso fica claro quando do exame da última das cenas que me propûs a analisar.

Em uma passagem-chave da comédia, Pisetero revela a natureza das asas prometidas. Após a saida de Cinésias, apresenta-se um delator profissional que quer voar para poder exercer com maior eficiência a sua profissão. Aconselhado por Pisetero a mudar de atividade, o delator nega-se e exige asas imediatamente. Diante da sua irredutibilidade, Pisetero confessa o segredo do seu poder:

DE. "Homem, nada de sermōes! Me dê as asas!

PI. Agora, enquanto falo, estou the dando asas.

DE. Ecomo?

Dar asas a alguém com palauras?

PI. Graças às palauras todos levantam vôo.

DE. Todos?

PI. Vocè nunca ouviu a conversa de sempre [1440]

dos pais com os adolescentes no barbeiro?

"Não é terrivel que Diütrefes, com sua lábia, tenha dado asas ao meu rapaz para as corridas?"

E um outro diz que o dele bateu asas por causa da tragédia e que vive nas nuvens. [1445]

DE. Então graças às palauras eles levantaram vôo?

PI. Isso mesmo.

Graças às palauras a mente fica suspensa nos ares / e o homem se eleva. Assim eu quero dar-the asas e com bons conselhos encaminhá-lo para uma profissāo decente. ${ }^{20}$ 
No diálogo entre Pisetero e o Delator, o sublime não surge mais representado, mas está teorizado. Pode-se dizer, guardadas as devidas proporçōes, que esse diálogo constitui uma pequena teoria do sublime, de caráter acidental, dentro da comédia.

Ao identificar as asas com as palavras, Pisetero observa que graças a elas o homem se eleva (epairetai, v. 1447). Porém não é mais o corpo que se projeta nos ares, mas o espirito (phrénas, $\mathrm{v}$. 1445) e a mente (noûs, v. 1447). Eis exposto com simplicidade o efeito do sublime sobre o ouvinte: elevar seu espirito, sensibilizálo, melhorá-lo. Cinésias, o poeta que quer virar uma ave para alçar vôo de corpo e alma, é expulso por não conceber que exista sentimento elevado sem que haja também um corpo em levitação. $O$ Delator também fica sem suas asas por não se deixar elevar pelas palavras, recusando-se a mudar sua conduta.

Essas idéias aproximam Aristófanes de Longino, que vai teorizar de fato sobre o estilo elevado cinco séculos mais tarde no Tratado sobre o Sublime. Compare-se o que diz Pisetero com o trecho em que Longino descreve os efeitos do sublime sobre o homem:

"Pois, por natureza de certa forma, sob o efeito do verdadeiro sublime, nossa alma (psyché) se eleva (epairetai) e, atingindo soberbos cumes, enche-se de alegria e exaltação, como se ela mesma tivesse criado o que ouviu. "21

A conclusão de Longino coincide totalmente com a de Pisetero. Em outra passagem do Tratado, ele vai ressalvar que a experiência do verdadeiro sublime se restringe às pessoas de sentimentos elevados, o que mais uma vez, está de acordo com o comportamento de Pisetero, ao se recusar a entregar asas a quem tem pensamentos rasteiros $^{22}$.

(21) Do Sublime, VII, 2, tradução de Filomena Hirata a partir de J. Pigeaud (1996). (22) Do Sublime, IX, 4. 

$n^{\prime}$ As Aves de Aristófanes. Lingua e Literatura, n²3, p. 15-27, 1997.

\section{AS ASAS DA IMAGINAÇĀO}

Assim, ao fim desses encontros, Pisetero continua a ser o único homem alado da peça, já que seu companheiro de aventura, Evélpides, deixou a cena para não mais voltar cerca de quinhentos versos antes. As suas asas são a sua habilidade com as palavras. $O$ que ele se torna se deve ao discurso, sua ascensão se deve às asas da imaginação e com essas será coroado o novo mestre do universo. Conseqũentemente toda a ação da comédia é fruto de palavras: o direito das aves à soberania, a construção da cidade aérea, a distribuição de asas para os mortais.

O lógos é o grande responsável pela sustentaçāo da cidade dos pássaros no ar, uma vez que ela nāo passa de uma construçāo retórica $^{23}$. A cena permanece a mesma desde o inicio da peça, o bosque onde reside Tereu, a poupa. Não há nenhum indício no texto de uma mudança de cenário. Só se tem notícias da nova cidade através dos relatos de mensageiros: palavras e mais palavras. Seu próprio nome, Cuconuvolândia, já revela a sua imaterialidade: nuvem, nêvoa, nada. A referência ao cuco, ave tida como astuciosa por botar seus ovos em ninhos de outros pássaros, para que esses criem seus filhotes, aponta para o ato de enganar. Ou seja, Cuconuvolândia soaria para um grego a algo como "Engana-Trouxa"

Pisetero cria Cuconuvolândia a partir do lógos e, assim como o alfaiate espertalhão de Andersen convence os súditos e o próprio imperador que ele está ricamente vestido em sua nudez, trata de persuadir as aves da realidade de sua cidade ${ }^{24}$. Essas vão reelaborar os argumentos que ele lhes oferece e se dirigir aos homens na parábase ${ }^{25}$, tentando, por sua vez, cooptá-los. Crentes os seres humanos da divindade dos pássaros e de que Cuconuvolândia é o novo centro do universo, os deuses abandonados também se curvam. $\hat{E}$

(23) Cf. WHITMAN (1964: 193-194).

(24) ANDERSEN, H. C. Os novos trajes do imperador. In: Contos de Andersen. Traduçāo de Guttorm Hanssen. Rio de Janeiro: Paz e Terra, 1987, p. 108. 113.

(25) As Aves, vv. 676-800. 
certo que, se Pisetero sabe tirar proveito de seu dom oratório, as aves não alcançam o mesmo êxito. Enquanto seu lider, divinizado pelo casamento sagrado com Soberania, torna-se tirano (sic) do universo, elas compoem apenas seu séquito admirado, estāo no mesmo plano que homens e deuses.

Se o comportamento de Pisetero deixa a desejar do ponto de vista ético e parece contrastar com a elevação que as asas-palavras lhe proporcionam, isso se deve ao fato de o herói cômico não se precisar se submeter a nenhuma regra que limita a atuação dos demais mortais. A malandragem é constitutiva do seu caráter, que se encontra acima da moral ${ }^{26}$. O protagonista pode exigir que seus interlocutores ajam com lisura, castigando-os em caso de recusa, mas está livre para usar de quaisquer meios para atingir os fins almejados. Digamos que sua função lhe confere certas imunidades.

Embora As Aves não deva ser vista como um roman-à-clefs, cuja alusão cifrada a um momento particular da vida política ateniense seja estrita, é significativo que sua composição coincida com um periodo de grande ufanismo e entusiasmo popular na histôria da cidade. Um ano antes de sua apresentação nas Grandes Dionisias, a assembléia, seduzida pelos vôos oratórios de Alcibiades, aprovara o envio de uma grande expedição militar à Sicilia, julgando que, se vencesse, seria uma potência imbativel na Hélade. Tomados pela euforia de ver concretizado tal objetivo, os cidadãos recusaram-se a pesar os prôs e contras de tamanha operação. Hoje, sabemos que o fim foi trágico para eles, determinando a derrota na Guerra do Peloponeso. Mas entāo, o aspecto mais visivel do episódio, devia estar no poder de persuasão das palavras, capaz de criar mundos novos e melhores e de sustentar o desejo da massa em alturas inimagináveis.

A estratégia de Aristófanes, ao optar pela abordagem indireta dos problemas de Atenas, foi fazer com que o espectador saisse do chão, do cotidiano, e se deixasse levar pelas asas da imaginação até a cidade aérea dos pássaros. $E$ tudo isso para que, no momento em que os atenienses se reconhecessem em Pisetero e à sua pró-

(26) Sobre a poneria do herói cômico: WHITMAN, C (1964). 
pria política no desejo ilimitado dele pelo poder, a sátira ao imperialismo de Atenas fosse mais contundente do que jamais fora antes. Com os espíritos desarmados, os cidadãos perceberiam do que as palavras sāo capazes e que a principal força da democracia podia estar voltada contra eles.

\section{BIBLIOGRAFIA}

ARISTÓFANES. A Paz. Traduçāo de SOUZA E SILVA, M. F. Coimbra: Instituto Nacional de Investigação Cientifica, 1989.

ARISTOPHANES. Birds. Edited and translated by SOMMERSTEIN, A. Wiltshire: Aris and Phillips, 1987

ARISTOTE. Politique (I-I). Ed. AUBONNET, J. Paris: Les Belles-Lettres, 1960.

COMOTTI, Giovanni. Greek Music. In: Music in Greek and Roman Culture.

Tradução de Rosária V. Munson. Baltimore: Johns Hopkins University Press, 1991, p. 12-97.

DOBROV, Gregory. Aristophanes' Birds and the metaphor of deferral. In: Arethusa, 23/2, 1990, p. 209 -233.

LONGINO. Do Sublime. Tradução de Filomena Hirata a partir de J. Pigeaud. São Paulo: Martins Fontes, 1996.

PARRY, Milman. About winged words. In: Parry, A. (ed.). The Making of Homeric Verse. New York: Oxford University Press, 1987 p. 414-418.

TAILlARDAT, Jean. Les Images d'Aristophane. Paris: Les Belles-Lettres, 1965.

VERNANT, Jean-Pierre. O universo espiritual da pólis. In: As Origens do Pensamento Grego. Tradução de Ísis B. Da Fonseca. São Paulo: DIFEL, 1981, p.34-47.

Whitman, Cedric. Aristophanes and the Comic Hero. Cambridge/ Massachusetts: Harvard University Press, 1964.

ABSTRACT: Aristophanes' Birds' main theme is the power of words. Though its plot may seem fantastic at first, the Athenian democracy is constantly referred to throughout the play, represented by its main pillar, 
i.e. public debate. Exploring several posssibilities of employing speech in convincing and manipulating people, of using words as the means to attain the most extravagant aims, Aristophanes puts on stage the true beneficiaries of rhethoric: poets, seers, lawyers, politicians. In sucessive confrontations to the hero, a brief theory of the sublime is sketched, as an attempt to describe the effects of speech upon man. Despite its brevity, this theory is surprisingly coincident with Longinus' definition, as developed, centuries later, in his essay On the Sublime.

Keywords: Ancient Greek Comedy, Aristophanes, Sublime. 